\title{
Isolated unilateral lichen sclerosus of the sole
}

\author{
Mohammad Adil', Syed Suhail Amin', Bushra Siddiqui², Mohsin Aijaz², \\ Mohd Mohtashim ${ }^{1}$, Mohammad Mudassir ${ }^{1}$
}

${ }^{1}$ Department of Dermatology, Jawaharlal Nehru Medical College, Aligarh Muslim University, Aligarh, India, ${ }^{2}$ Department of Pathology, Jawaharlal Nehru Medical College, Aligarh Muslim University, Aligarh, India

Corresponding author: Dr. Mohammad Adil, E-mail: dr.mohd.adil@gmail.com

\begin{abstract}
Extragenital involvement in lichen sclerosus is uncommon. Involvement of the palms and soles is very rare, with lichen sclerosus almost always showing elsewhere on the body. We describe the case of a female child with a linear hyperpigmented plaque on the right sole studded with keratotic papules. Dermoscopy showed scales and keratin plugs with surrounding pigmentation. Histopathology showed features of lichen sclerosus. This report describes a very rare occurrence of unilateral and isolated involvement of the sole with lichen sclerosus and its dermoscopic findings.
\end{abstract}

Key words: Lichen sclerosus; Lichen sclerosus et atrophicus; Dermoscopy; Follicular plugging

\section{INTRODUCTION}

Lichen sclerosus, also known as lichen sclerosus et atrophicus, is a chronic inflammatory disease that commonly affects the genitals. Extragenital involvement is seen in around $15-20 \%$ of cases [1]. Isolated involvement of the palms or soles is extremely rare. Herein, we report a case of isolated unilateral lichen sclerosus of the sole in a female with dermoscopic and histopathological findings of this rare presentation.

\section{CASE REPORT}

A ten-year-old female presented herself to us with asymptomatic discoloration on the right sole persistent for the last eight months. On examination, a linear atrophic hyperpigmented plaque $5 \mathrm{~cm} \times 2 \mathrm{~cm}$ in size was present on the right sole, extending from the midfoot to the proximal part of the heel (Fig. 1). The plaque was studded with small keratotic papules. The rest of the cutaneous examination, including the genitals, was normal. Dermoscopy of the plaque showed scaling and keratin plugs surrounded by a rim of pigmentation and scales (Fig. 2). Histopathology of the area showed hyperkeratosis, flattened rete ridges, homogenous and hyalinized dermal collagen, adnexal plugging, and a mild chronic superficial inflammatory infiltrate (Fig. 3). Based on these findings, a diagnosis of lichen sclerosus of the sole was reached.

\section{DISCUSSION}

Lichen sclerosus (LS) is a benign chronic inflammatory disease of unknown etiology with a clear female preponderance [2]. Autoimmunity, trauma and chronic irritation, genetic factors, hormonal influences, and infections have been proposed as the pathogenesis of the disease [3]. LS commonly affects the genitals and manifests itself as severely pruritic porcelain-white plaques with erosions, fissures, and atrophy, often leading to deformity of the external genitalia. On the extragenital areas, it presents itself as asymptomatic shiny white macules or plaques with follicular plugs. The common extragenital sites are the upper trunk, neck, arms, legs, ears, and nose [2]. Involvement of the palmoplantar skin is extremely rare and has almost always been described with lichen sclerosus also present on other areas [1-5]. The volar lesions have been described as papules and plaques ranging from white to erythematous and sometimes having keratotic papules on them [4].

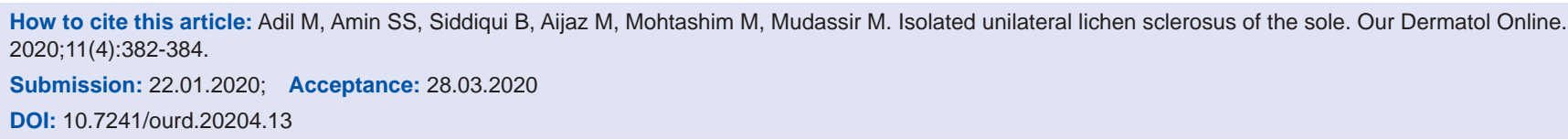




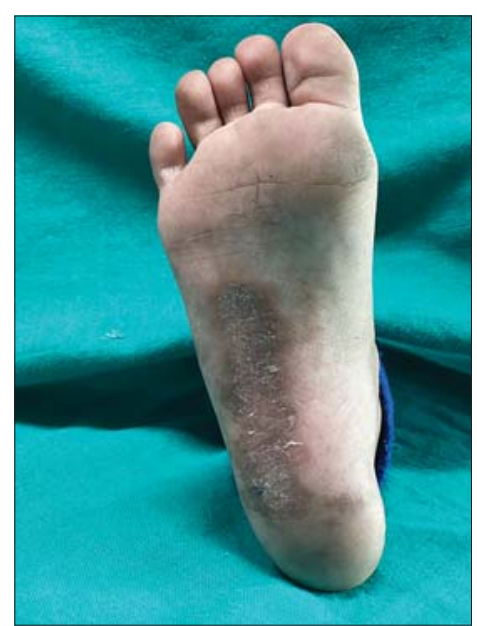

Figure 1: A linear atrophic plaque on the right sole.

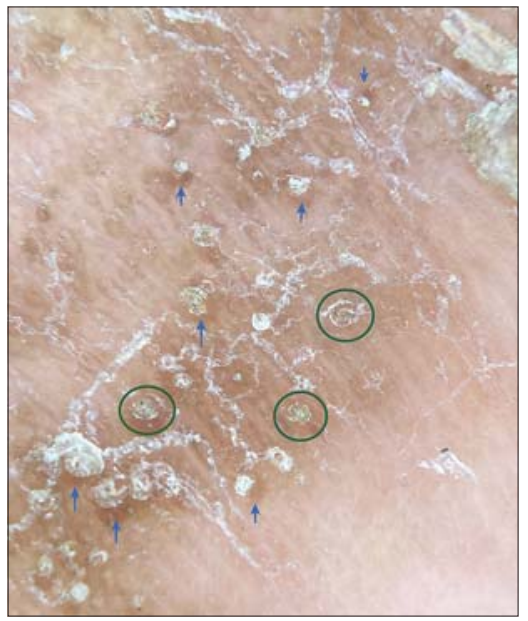

Figure 2: Polarized dermoscopy of the plaque showing scaling, adnexal plugs with pigment accentuation (blue arrow) and surrounding scales (green circles). (DermLite 4, 10x).

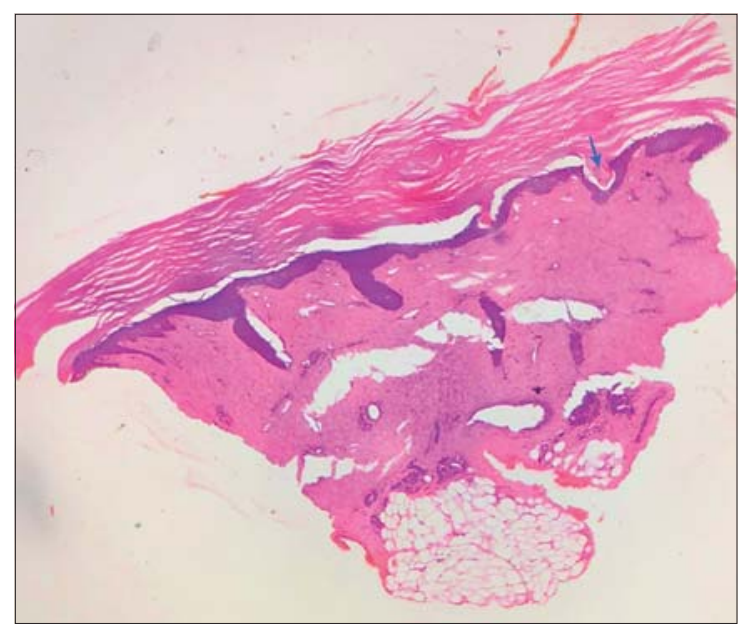

Figure 3: Hyperkeratosis and flattened rete ridges in the epidermis, homogenous and hyalinized dermal collagen with mild superficial chronic infiltrates in the dermis; adnexal plugging (blue arrow) seen at one end of the section (H\&E, 40x).
Dermoscopy of extragenital lichen sclerosus reveals white structureless areas, comedo-like openings, comma vessels, hairpin-like vessels, and dotted vessels [6,7]. A dermoscopic examination of a palmoplantar location has probably never been done. While we found comedo-like openings, white structureless areas or vessels were not observed. This could have been due to the thickness of the volar skin. The presence of comedolike openings is interesting as hair follicles are absent from the volar skin. However, keratotic papules on the palms in lichen sclerosus have been described [4]. We believe that these might be due to plugging of other skin adnexa.

Histopathology of lichen sclerosus shows hyperkeratosis, thinning of rete ridges, basal cell vacuolization, homogenous collagen, superficial perivascular infiltrate, and follicular plugging.

The differential diagnosis in our case included lichen sclerosus, morphea, lichen planus, and punctate palmoplantar keratoderma. Lichen planus is extremely itchy and shows colloid bodies and band-like infiltrates. Punctate palmoplantar keratoderma does not show epidermal atrophy, adnexal plugs, or an inflammatory infiltrate in the dermis. Morphea does not show adnexal plugging or basal cell degeneration. Although morphea and lichen sclerosus are considered two separate disease entities, some controversy still lingers around the two being different facets of the same disease, with coexistent lesions and one transitioning into the other [8].

The treatment of lichen sclerosus includes highpotency topical steroids, other immunomodulators, systemic retinoids, estrogen, and phototherapy, but the recurrence rate is high [9]. Surgical modalities may be needed in the case of stricture and deformity of the genitals.

We present a case of isolated unilateral lichen sclerosus of the sole and describe the dermoscopic findings of volar lichen sclerosus, which, to the best of our knowledge, has not been done before.

\section{Consent}

The authors certify that they have obtained all appropriate patient consent forms, in which the patients gave their consent for images and other clinical information to be included in the journal. The patients understand that their names and initials will not be published and due effort will be made to conceal their identity, but that anonymity cannot be guaranteed. 


\section{REFERENCES}

1. Aggarwal K, Jain V K, Brahma D. Palmo-plantar lichen sclerosus et atrophicus. Indian J Dermatol Venereol Leprol. 2003;69:43-4.

2. Viana FO, Cavaleiro LHS, Unger DAA, Miranda MFR, Brito AC. Acral lichen sclerosus et atrophicus- case report. An Bras Dermatol. 2011;86(4 Suppl 1):S82-4.

3. Fistarol SK, Itin PH. Diagnosis and treatment of lichen sclerosus. An update. Am J Clin Dermatol. 2013;14:27-47.

4. Steff M, Toulemonde A, Croue A, Lemerle E, Le Corre Y, Verret J-L. Acral lichen sclerosus et atrophicus. Ann Dermatol Venereol. 2008;135-201-4.

5. Purres J, Krull EA. Lichen sclerosus et atrophicus involving the palms. Arch Dermatol. 1971;104:68-9.

6. Ankad BS, Beergouder SL. Dermoscopic patterns in lichen sclerosus: A report of three cases. Indian Dermatol Online J.
2015;6:237-40.

7. Shim W-H, Jwa S-W, Song M, Kim H-S, Ko H-C, Kim M-B, et al. Diagnostic usefulness of dermatoscopy in differentiating lichen sclerosus et atrophicus from morphea. J Am Acad Dermatol. 2012;66:690-1.

8. Ganesan L, Parmar H, Das JK, Gangopadhyay A. Extragenital lichen sclerosus et atrophicus. Indian J Dermatol. 2015;60:420.

9. Mori T, Yamamoto T. Extra-genital lichen sclerosus in a patient with anti-SS-A antibody. Our Dermatol Online. 2019;10:310-1.

Copyright by Mohammad Adil, et al. This is an open access article distributed under the terms of the Creative Commons Attribution License, which permits unrestricted use, distribution, and reproduction in any medium, provided the original author and source are credited.

Source of Support: Nil, Conflict of Interest: None declared. 